\title{
High-resolution melting curve analysis for infectious bronchitis virus strain differentiation
}

\author{
Mustafa Ababneh, Ola Ababneh and Mohammad Borhan Al-Zghoul
}

Department of Basic Medical Veterinary Sciences, Jordan University of Science and Technology, Irbid 22110, Jordan.

Corresponding author: Mustafa Ababneh, e-mail: ababnem@just.edu.jo

Co-authors: OA: olla.a.a.1993@gmail.com, MBA: alzghoul@just.edu.jo

Received: 13-09-2019, Accepted: 13-01-2020, Published online: 03-03-2020

doi: www.doi.org/10.14202/vetworld.2020.400-406 How to cite this article: Ababneh M, Ababneh O, Al-Zghoul MB (2020) High-resolution melting curve analysis for infectious bronchitis virus strain differentiation, Veterinary World, 13(3): 400-406.

\begin{abstract}
Background and Aim: Belonging to the Coronaviridae family, avian infectious bronchitis virus (IBV) causes respiratory, reproductive, and renal diseases in poultry. Preventative measures lie mainly in vaccination, while the gold standard for IBV classification and differentiation is based on the sequence analysis of the spike 1 (S1) gene. In this study, we tested a new assay for IBV strain classification that is less expensive and requires reduced time and effort to perform. We carried out a quantitative real-time polymerase chain reaction followed by high-resolution melting (qRT-PCR/HRM) curve analysis.

Materials and Methods: In this study, qRT-PCR was conducted on a partial fragment S1 gene followed by a high resolution melting curve analysis (qRT-PCR/HRM) on 23 IBV-positive samples in Jordan. For this assay, we utilized the most common IBV vaccine strains (Mass and 4/91) as a reference in the HRM assay. To evaluate the discrimination power of the qRT-PCR/ HRM, we did the sequencing of the partial S1 gene.

Results: It was shown that HRM was able to classify IBV samples into four clusters based on the degree of similarity between their melting points: The first cluster exhibited the highest similarity to the 4/91 strain, while the second was similar to the Mass-related IBV strain. Although the third cluster contained the highest number of samples, it displayed no similarity to any of the reference vaccine strains, and, after comparing them with the sequencing results, we found that the samples in the third cluster were similar to the variant II-like (IS-1494-06) IBV field strain. Finally, the fourth cluster comprised one unique sample that was found to belong to the Q1 IBV strain.
\end{abstract}

Conclusion: Our developed qRT-PCR/HRM curve analysis was able to detect and rapidly identify novel and vaccinerelated IBV strains as confirmed by S1 gene nucleotide sequences, making it a rapid and cost-effective tool.

Keywords: high-resolution melting curve analysis, infectious bronchitis virus, spike 1 gene.

\section{Introduction}

Avian infectious bronchitis (IB) serves as a major threat to the worldwide poultry industry, and it is a disease endemic to Jordan, causing respiratory, renal, and reproductive problems in chickens $[1,2]$. IB virus (IBV) is a positive-sense single-stranded RNA virus, belonging to the Coronavirinae subfamily gamma-coronaviruses [3]. IBV was first recognized as an avian respiratory pathogen in 1930, and its genetic diversity has resulted in the introduction of many IBV vaccines [4]. Recently, emerging IBV variants have been reported to cause nephropathogenic and reproductive problems, which are a turn of events that require a dramatic change in vaccination programs $[5,6]$.

The IBV genomehasan approximatesize of 27,500 nucleotides and is organized in the following order: UTR5'-POl-S-3a-3b-E-M-4b-4c-5a-5b-N-UTR3' [7].

Copyright: Ababneh, et al. Open Access. This article is distributed under the terms of the Creative Commons Attribution 4.0 International License (http://creativecommons.org/licenses/ by/4.0/), which permits unrestricted use, distribution, and reproduction in any medium, provided you give appropriate credit to the original author(s) and the source, provide a link to the Creative Commons license, and indicate if changes were made. The Creative Commons Public Domain Dedication waiver (http:// creativecommons.org/publicdomain/zero/1.0/) applies to the data made available in this article, unless otherwise stated.
The spike glycoprotein gene, encoding spike protein subunit 1 (S1) and 2 (S2), is the most variable gene in the IBV genome $[8,9]$. In particular, the S1 protein, which is responsible for viral attachment and entry into host cells, differs significantly with regard to amino acid sequence among IBV serotypes [10]. This variability makes the $\mathrm{S} 1$ gene an ideal target in viral typing assays incorporating reverse transcription-polymerase chain reaction (PCR) and DNA sequencing techniques. In most cases, high $\mathrm{S} 1$ gene homology between two strains can predict the occurrence of cross-protective immunity, where exposure to one strain confers protection to another [10-12].

IBV strains can be classified into six genotypes that together comprise 32 distinct viral lineages, the majority of which belong to genotype 1 [13]. In the Middle East, the common circulating IBV strains are the Massachusetts (Mass) and H120 vaccine strains as well as the D274, IBV variant I (793/B, IS/222/96, IS/251/96, and IS/64714/96) and variant II strains (IS/223/96, IS/572/98, IS/585/98, and IS/589/98) [1]. By the end of 2009, variant II and variant II-like strains appeared in Jordan (unpublished data) and North Iraq, and, in 2011, the unique IBV Q1 strain was reported in Jordan, Iraq, and Saudi Arabia [14]. For clinical purposes, IBV is diagnosed using RT-PCR and quantitative real-time PCR (qRT-PCR), but, for 
strain identification, sequencing of the full $\mathrm{S} 1$ gene or one of its fragments is performed [13,15].

High-resolution melting (HRM) curve analysis is a newly established PCR-based technique that has been used to differentiate related strains of the same animal or avian virus [16-19]. This technique was performed on double-stranded DNA resulting in rapid genotyping of genetic polymorphisms in diagnostic and routine [20]. This study aimed to optimize an HRM assay for genotyping the IBV vaccine and field strains found in Jordan.

\section{Materials and Methods}

\section{Ethical approval}

Approval from the Jordan University of science and technology animal care and use committee (JUSTACUC) is not applicable as these samples were collected from recently dead chickens in private farms, and then samples were submitted to our laboratory.

\section{Vaccine and field strains}

IBV vaccines were purchased from local Jordanian markets. The most commonly used IBV vaccine strains in Jordan are Mass-type strains (M41, MA5, and H120) as well as the 4/91 (793/B) vaccine strain (Table-1). These vaccines were used as reference IBV strains in the qRT-PCR/HRM procedure. Twenty-three positive IBV multi-tissue samples collected from different regions of Jordan during various outbreaks were also used (Table-2). Viral RNA of these samples and IBV vaccine strains were extracted, then went through cDNA synthesis, and then nested PCR amplification of a spike 1 gene fragment. To differentiate between IBV strains, the PCR products from the second round of nested S1 gene PCR were subjected to HRM analysis on the Rotor-Gene Q 5plex HRM Platform (Qiagen, CA, USA).

\section{RNA extraction and cDNA synthesis}

The IBV vaccine vials were rehydrated with $1 \mathrm{ml}$ of $1 \times$ PBS, then mixed by vortexing to dissolve the vaccines. A $150 \mu 1$ of the rehydrated vaccine was added to $250 \mu \mathrm{l}$ of TRI Reagent (Zymo Research, USA) and suspended for $5 \mathrm{~min}$ in a $50^{\circ} \mathrm{C}$ dry bath. Then, $400 \mu$ l of absolute ethanol was added, and RNA extraction was performed using the Direct-zol RNA MiniPrep kit (Zymo Research, USA). IBV field samples, mostly consisting of tracheal and kidney tissues that were submitted to our laboratory for IBV diagnosis, were homogenized and centrifuged at $3000 \times g$ for $5 \mathrm{~min}$. After that, $150 \mu \mathrm{l}$ of the supernatant was mixed with $250 \mu 1$ of Trizol. A SuperScript ${ }^{\circledR}$ IV First-Strand Synthesis kit (Invitrogen, USA) was used according to the manufacturer's instructions to make cDNA for both the vaccine and field samples.

\section{Nested RT-PCR amplification of spike gene}

Nested RT-PCR amplification was performed using the synthesized cDNA to amplify S1 gene fragments of the IBV genome. The first and second rounds nested PCR was performed in a reaction volume of
Table-1: The IBV vaccine strains used as a reference in this study.

\begin{tabular}{lll}
\hline Vaccine ID & Commercial name & IBV strain \\
\hline IV & IB Mass & Mass 41 \\
$2 \mathrm{~V}$ & IB 4/91 & $4 / 91(793 / \mathrm{B})$ \\
$3 \mathrm{~V}$ & IB 88 & CR 88 variant strain \\
& & (close to 793/B) \\
$4 \mathrm{~V}$ & CEVAC I BIRD & $1 \backslash 96$ (close to 793/B) \\
$5 \mathrm{~V}$ & Cevac Brone 120 I & H 120 \\
\hline
\end{tabular}

IB: Infectious bronchitis, IBV: IB virus

Table-2: The IBV field isolates used in this study

\begin{tabular}{lcl}
\hline Number & Sample ID & Tissue type \\
\hline 1 & T1 & Trachea \\
2 & T2 & Trachea \\
3 & T3 & Trachea \\
4 & T4 & Trachea \\
5 & T5 & Trachea \\
6 & L1 & Lung \\
7 & L2 & Lung \\
8 & K1 & Kidney \\
9 & K2 & Kidney \\
10 & 20417 & Unknown \\
11 & 21417 & Unknown \\
12 & 22417 & Unknown \\
13 & $51216 \mathrm{D}$ & Trachea and cecal tonsils \\
14 & $61216 \mathrm{D}$ & Cecal tonsils \\
15 & $71216 \mathrm{D}$ & Cecal tonsils and kidney \\
16 & $101216 \mathrm{D}$ & Kidney \\
17 & $6417 \mathrm{P}$ & Lung and trachea \\
18 & $7417 \mathrm{P}$ & Lung and trachea \\
19 & $8417 \mathrm{P}$ & Lung and trachea \\
20 & $010217 \mathrm{P}$ & Lung and trachea \\
21 & $050617 \mathrm{P}$ & Allantoic fluid \\
22 & D10117 & Brain \\
23 & $7 P 6$ & Unknown \\
\hline
\end{tabular}

$25 \mu 1$ that contained $2.5 \mu 1$ of $10 \times$ PCR buffer without magnesium, $1 \mu \mathrm{dNTPs}, 1 \mu \mathrm{l}$ of each reverse and forward primers, $0.75 \mu 1 \mathrm{MgCl}_{2}, 0.1 \mu \mathrm{Taq}$ DNA polymerase, $1 \mu \mathrm{cDNA}$, and $18.15 \mu \mathrm{l} \mathrm{H}_{2} \mathrm{O}$. Thirty-five cycles of amplification were carried out in a thermocycler, with each cycle consisting of denaturation for $45 \mathrm{~s}$ at $94^{\circ} \mathrm{C}$, annealing for $1 \mathrm{~min}$ at $50^{\circ} \mathrm{C}$ (for both rounds), and extension for $2 \mathrm{~min}$ at $72^{\circ} \mathrm{C}$, and a final extension for $7 \mathrm{~min}$ at $72^{\circ} \mathrm{C}$. Electrophoresis of amplified products was carried out using $1.5 \%$ agarose gel, which was visualized and photographed under UV light with a $100 \mathrm{bp}$ ladder. Nested PCR primer sequences for the S1 gene were as previously reported [14].

\section{QRT-PCR/HRM}

For this assay, the nested RT-PCR for the amplification of S1 fragment was repeated. However, the S1 RT-PCR products from the first round of nested RT-PCR were used as a template in the HRM protocol. A Type-it HRM PCR Kit (Qiagen, CA, USA) was employed according to the manufacturer's instructions on the Qiagen Rotor-Gene Q 5plex HRM Platform (Qiagen, CA, USA). The qRT-PCR $25 \mu 1$ reaction volume contained $12.5 \mu 1$ of $2 \times$ HRM PCR master mix, $1.75 \mu \mathrm{l}$ of each $10 \mu \mathrm{M} \mathrm{S} 1$ gene internal primers for the second round, and $2 \mu 1$ of S1 RT-PCR product from 
the first round of nested PCR. The optimized cycling protocol for HRM analysis on the Qiagen Rotor-Gene Q 5plex HRM consisted of the following conditions: An initial PCR activation step for $5 \mathrm{~min}$ at $95^{\circ} \mathrm{C}$ followed by 40 cycles involving denaturation for $10 \mathrm{~s}$ at $95^{\circ} \mathrm{C}$, annealing for $30 \mathrm{~s}$ at $55^{\circ} \mathrm{C}$, and extension for 10 $\mathrm{s}$ at $72^{\circ} \mathrm{C}$. HRM is for $2 \mathrm{~s}$ from 65 to $95^{\circ} \mathrm{C}$ with 0.1 , 0.2 , and $0.3^{\circ} \mathrm{C}$ increments.

\section{HRM analysis}

Two softwares were used for the analysis of the HRM results. The operating HRM software installed on the Rotor-Gene Q 5plex machine and the RotorGene ScreenClust HRM software (Qiagen, CA, USA) was used to analyze the results of HRM and to assign the different IBV strains into clusters according to their HRM patterns. The HRM analysis using the operating software was done by setting a reference IBV genotype either as 4/91, Mass, or variant II genotypes, after normalizations, the HRM genotype confidence percentages (GCPs) were obtained. For the ScreenClust software, the unsupervised model was used and then data were normalized and clusters were generated to contain all IBV isolates. The typicality and probability of each sample was recorded.

\section{Sequencing of partial S1 fragments and sequence analysis}

The S1 RT-PCR products of the nested RT-PCR amplification were treated with ExoSAP-IT PCR Product Cleanup Reagent (Cat. No: 78201, Thermo Fisher Scientific, USA) according to the manufacturer's instructions. Briefly, $2 \mu 1$ of ExoSAP enzyme were added to $5 \mu 1$ of the product then incubated at $37^{\circ} \mathrm{C}$ for $15 \mathrm{~min}$ to degrade remaining primers and nucleotides followed by another incubation at $80^{\circ} \mathrm{C}$ for $15 \mathrm{~min}$ to inactivate the ExoSAP-IT reagent. The cleaned RT-PCR products were sent to a sequencing facility (Macrogen, South Korea) to be sequenced by chain termination technology. S1 sequences were viewed on the BioEdit software and edited by the Edit Sequence interface of the Lasergene package. Sequence alignment, calculation of the sequence nucleotide similarities, and construction of the phylogenetic tree were done by the MegAlign interface of the Lasergene package. The partial sequences of S1 gene of all IBV isolates included in this study were deposited in GenBank under the accession numbers; MK680008-MK6800034.

\section{Results}

Molecular characterization (QRT-PCR/HRM and partial S1 sequencing)

To detect the field and vaccine IBV strains, we used a nested RT-PCR assay to detect the S1 gene. Twenty-two out of the 23 samples were positive for the S1 gene after nested RT-PCR. Those 22 samples, along with the five IBV vaccine reference strains, were subjected to qRT-PCR targeting the S1 gene followed with HRM curve analysis. Table-3 summarizes the results for HRM and ScreenClust analysis as well as the sequencing of the 22 IBV field samples and 5 IBV vaccine samples (a total of 27 samples).

Table-3: Correlation between the HRM melting temperature, the cluster numbers according to the ScreenClust software, and the sequencing results.

\begin{tabular}{|c|c|c|c|c|}
\hline Number & Sample ID & HRM melting temp. & Screen plot cluster & Sequencing result \\
\hline 1 & $1 \mathrm{~V}$ & 78.24 & CLUSTER 2 & Mass \\
\hline 2 & $2 \mathrm{~V}$ & 78.36 & CLUSTER 1 & $4 \backslash 91$ \\
\hline 3 & $3 \mathrm{~V}$ & 77.79 & CLUSTER 1 & CR 88 variant strain very close to $4 \backslash 91$ \\
\hline 4 & $4 \mathrm{~V}$ & 78.09 & CLUSTER 1 & $1 \backslash 96$ very close to $4 \backslash 91$ \\
\hline 5 & $5 \mathrm{~V}$ & 78.39 & CLUSTER 2 & $\mathrm{H}-120$ very close to Mass \\
\hline 6 & T1 & 78.81 & CLUSTER 2 & Mass \\
\hline 7 & $\mathrm{~T} 2$ & 78.39 & CLUSTER 2 (borderline of cluster 2 ) & Variant II - mismatch \\
\hline 8 & T3 & 78.36 & CLUSTER 2 & Mass \\
\hline 9 & T4 & 78.36 & CLUSTER 2 & Mass \\
\hline 10 & T5 & 78.36 & CLUSTER 2 & Mass \\
\hline 11 & L1 & 78.90 & CLUSTER 3 & Variant II \\
\hline 12 & L2 & 78.45 & CLUSTER 2 & Mass \\
\hline 13 & K1 & 79.05 & CLUSTER 3 & Variant II \\
\hline 14 & $\mathrm{~K} 2$ & 78.39 & CLUSTER 2 & Mass \\
\hline 15 & 20417 & 78.90 & CLUSTER 3 & Variant II \\
\hline 16 & 21417 & 78.75 & CLUSTER 3 & Variant II \\
\hline 17 & 22417 & 78.60 & CLUSTER 3 & Variant II \\
\hline 18 & 51216D & 78.81 & CLUSTER 3 & Variant II \\
\hline 19 & 61216D & 78.75 & CLUSTER 2 (borderline of cluster 3 ) & Variant II - mismatch \\
\hline 20 & 101216D & 78.30 & CLUSTER 1 & $4 \backslash 91$ \\
\hline 21 & 6417P & 78.30 & CLUSTER 3 & Variant II \\
\hline 22 & 7417P & 78.51 & CLUSTER 2 & Mass \\
\hline 23 & 8417P & 78.75 & CLUSTER 3 & Variant II \\
\hline 24 & 072017P & 78.69 & CLUSTER 4 & Q1 \\
\hline 25 & 0605P & 78.45 & CLUSTER 2 & Variant II - mismatch \\
\hline 26 & D10117 & 77.45 & CLUSTER 1 & $4 \backslash 91$ \\
\hline 27 & 7P6 & 77.49 & CLUSTER 1 & $4 \backslash 91$ \\
\hline
\end{tabular}

HRM: High-resolution melting 
The clusters are produced by the ScreenClust software into four clusters with the typicality and probability of each sample to be in one of the four clusters (Figure-1). Furthermore, the HRM GCPs of selected samples are shown in Figure-2. The sequencing of the partial S1 gene was carried out to confirm the results of the HRM assay (Figure-3). The sequencing of the partial S1 gene for all five IBV vaccine strains matched $100 \%$ with their identity. Out of the 22 field samples, three samples were found to be IBV 4/91like strain on sequencing and on HRM analysis. Out of the 22 field samples, seven samples were confirmed with sequencing and HRM analysis to be of Masslike strain. Eleven IBV field samples were found to be of IBV variant II-like (IS-1494-06) field strain (on HRM, 8/11 were also of variant II-like and 3/11 were of Mass like) and one field sample was a unique IBV strain (Q1 strain). The HRM assay divided the IBV vaccine and field strains into four different clusters.

\section{Cluster 1}

The first cluster consisted of the IBV 4/91 and IBV 4/91-like strains. Three vaccines and three field isolates were located in this cluster. The IBV strain 4/91 can be found both as a vaccine and as a field strain and many IBV infections in different countries have been linked to $4 / 91$ field strains. The IBV field samples (D10117, 101216D, and 7P6) belonged to cluster 1, representing the 4/91 and IBV 4/91-like strains, respectively. Based on HRM analysis, the melting temperature of the $101216 \mathrm{D}$ sample $\left(78.30^{\circ} \mathrm{C}\right)$ was close to that of the $4 \mathrm{~V}(1 / 96)$ strain $\left(78.09^{\circ} \mathrm{C}\right)$, while the melting temperatures of the 7P6 sample $\left(77.49^{\circ} \mathrm{C}\right)$ and the $3 \mathrm{~V}(\mathrm{CR} 88$ variant $)$ strain $\left(77.09^{\circ} \mathrm{C}\right)$ were similarly close. Despite the variation in melting temperatures between the vaccine and field strains in cluster 1, HRM and ScreenClust analysis were still able to identify the similarities between them by classifying them into the same cluster.

\section{Cluster 2}

The second cluster contained the IBV Mass and Mass-like strains. Two IBV vaccine strains were located in this cluster along with 10 field IBV isolates, three of which were found to be of a variant II-like (1S/1494/06-like) strains on sequencing (T2, 61216D and 0605P). While cluster 2, which includes IBV mass and mass like strains, has a closer range between the melting temperatures (78.24-78.51) with less variation up to 0.27 . This indicates that the viruses of the field samples share close sequences to the Mass vaccine strain.

\begin{tabular}{|c|c|c|c|c|c|c|c|}
\hline \multirow[b]{2}{*}{ ID } & \multirow[b]{2}{*}{ Name } & \multirow[b]{2}{*}{ Cluster } & \multirow[b]{2}{*}{ Typicality } & \multicolumn{4}{|c|}{ Probabilities } \\
\hline & & & & Cluster 1 & Cluster 2 & Cluster 3 & Cluster 4 \\
\hline 1 & $1 \mathrm{~V}$ & Cluster 2 & 0.46797870 & 0.0000 & 1.0000 & 0.0000 & 0.0000 \\
\hline 2 & $2 \mathrm{~V}$ & Cluster 1 & 0.45265296 & 1.0000 & 0.0000 & 0.0000 & 0.0000 \\
\hline 3 & $3 \mathrm{~V}$ & Cluster 1 & 0.51071189 & 1.0000 & 0.0000 & 0.0000 & 0.0000 \\
\hline 4 & $4 \mathrm{~V}$ & Cluster 1 & 0.54845363 & 1.0000 & 0.0000 & 0.0000 & 0.0000 \\
\hline 5 & $5 \mathrm{~V}$ & \begin{tabular}{|l|} 
Cluster 4 \\
\end{tabular} & 0.51341712 & 0.0000 & 0.0000 & 0.0000 & 1.0000 \\
\hline 6 & $6 \mathrm{~V}$ & \begin{tabular}{|l|} 
Cluster 2 \\
\end{tabular} & 0.46707009 & 0.0000 & 1.0000 & 0.0000 & 0.0000 \\
\hline 7 & $\mathrm{~T} 1$ & Cluster 2 & 0.39554038 & 0.0002 & 0.9998 & 0.0000 & 0.0000 \\
\hline 8 & $\mathrm{~T} 2$ & Cluster 2 & 0.11645983 & 0.0000 & 0.9951 & 0.0049 & 0.0000 \\
\hline 9 & $T 3$ & Cluster 2 & 0.24671877 & 0.0011 & 0.9989 & 0.0000 & 0.0000 \\
\hline 10 & $\mathrm{~T} 4$ & Cluster 2 & 0.96997925 & 0.0000 & 1.0000 & 0.0000 & 0.0000 \\
\hline 11 & T5 & Cluster 2 & 0.74193990 & 0.0000 & 1.0000 & 0.0000 & 0.0000 \\
\hline 12 & 11 & Cluster 3 & 0.09285232 & 0.0000 & 0.0000 & 1.0000 & 0.0000 \\
\hline 13 & 12 & Cluster 2 & 0.46860810 & 0.0000 & 1.0000 & 0.0000 & 0.0000 \\
\hline 14 & K1 & Cluster 3 & 0.12767435 & 0.0000 & 0.0000 & 1.0000 & 0.0000 \\
\hline 15 & $K 2$ & \begin{tabular}{|l|} 
Cluster 2 \\
\end{tabular} & 0.87362757 & 0.0000 & 1.0000 & 0.0000 & 0.0000 \\
\hline 16 & 20417 & Cluster 3 & 0.71833160 & 0.0000 & 0.0007 & 0.9993 & 0.0000 \\
\hline 17 & 21417 & Cluster 3 & 0.84375891 & 0.0000 & 0.0002 & 0.9998 & 0.0000 \\
\hline 18 & 22417 & Cluster 2 & 0.08889530 & 0.0000 & 0.9968 & 0.0032 & 0.0000 \\
\hline 19 & 512160 & Cluster 3 & 0.61661269 & 0.0000 & 0.0000 & 1.0000 & 0.0000 \\
\hline 20 & 612160 & Cluster 2 & 0.06742204 & 0.0000 & 0.5732 & 0.4268 & 0.0000 \\
\hline 21 & $71216 \mathrm{D}$ & Cluster 4 & 0.51341712 & 0.0000 & 0.0000 & 0.0000 & 1.0000 \\
\hline 22 & $101216 \mathrm{D}$ & Cluster 1 & 0.57474930 & 1.0000 & 0.0000 & 0.0000 & 0.0000 \\
\hline 23 & $6417 \mathrm{P}$ & \begin{tabular}{|l|l|} 
Cluster 3 \\
\end{tabular} & 0.72273375 & 0.0000 & 0.0017 & 0.9983 & 0.0000 \\
\hline 24 & $7417 \mathrm{P}$ & Cluster 2 & 0.96824526 & 0.0000 & 1.0000 & 0.0000 & 0.0000 \\
\hline 25 & $8417 \mathrm{P}$ & Cluster 3 & 0.77410975 & 0.0000 & 0.0012 & 0.9988 & 0.0000 \\
\hline 26 & $012017 \mathrm{P}$ & \begin{tabular}{|l|} 
Cluster 2 \\
\end{tabular} & 0.92913169 & 0.0000 & 1.0000 & 0.0000 & 0.0000 \\
\hline 27 & $0605 \mathrm{P}$ & Cluster 2 & 0.57277463 & 0.0000 & 1.0000 & 0.0000 & 0.0000 \\
\hline 28 & D10117 & Cluster 4 & 0.51341712 & 0.0000 & 0.0000 & 0.0000 & 1.0000 \\
\hline 29 & 7P6 & Cluster 1 & 0.25134044 & 1.0000 & 0.0000 & 0.0000 & 0.0000 \\
\hline
\end{tabular}

Figure-1: The ScreenClust output showing the four clusters of the unsupervised model with the typicality and probability of each sample to be in one of the four clusters. 


\begin{tabular}{|c|c|c|c|}
\hline No. & \begin{tabular}{|l|l|} 
C & Name \\
\end{tabular} & Genotype & Confidence $\%$ \\
\hline 2 & Mass K2 & mass & 100.00 \\
\hline 3 & Varll 22417 & var11 & 100.00 \\
\hline 4 & $0605 P$ & mass & 80.57 \\
\hline 5 & 21417 & mass & 81.30 \\
\hline 6 & 20417 & mass & 95.00 \\
\hline 7 & 512160 & var11 & 83.52 \\
\hline 8 & 612160 & var11 & 97.93 \\
\hline 9 & 712160 & var11 & 76.92 \\
\hline 10 & 0100117 & var11 & 86.60 \\
\hline 11 & $101216 D$ & var11 & 91.60 \\
\hline 12 & $6417 \mathrm{P}$ & mass & 83.42 \\
\hline 13 & $7417 \mathrm{P}$ & mass & 98.67 \\
\hline 14 & $8417 \mathrm{P}$ & var11 & 94.93 \\
\hline 15 & $010217 P$ & mass & 95.44 \\
\hline 16 & L1 & var11 & 95.31 \\
\hline 17 & L2 & var11 & 96.58 \\
\hline
\end{tabular}

Figure-2: HRM genotype confidence percentages of selected IBV samples after normalization of the data.

\section{Cluster 3}

The third cluster contained the IBV variant II-like (1S/1494/06-like) strains, and only field isolates were found in this cluster. This cluster has the highest difference in the melting temperature that reaches 0.75 . Eight samples were of variant II-like (1S/1494/06 like) IBV strain representing $34 \%$ of the total IBV samples.

\section{Cluster 4}

The fourth and final cluster included one IBV field strain (072017), the latter of which was found to be Q1-like strain on sequencing.

\section{Discussion}

HRM analysis has been used to detect and genotype fowl adenoviruses, avian influenza virus, and avian nephritis virus, among others [17,21,22]. The first published study to use HRM analysis to the type of IBV strains was carried out in Australia, where an HRM assay that targeted the 3'UTR gene was

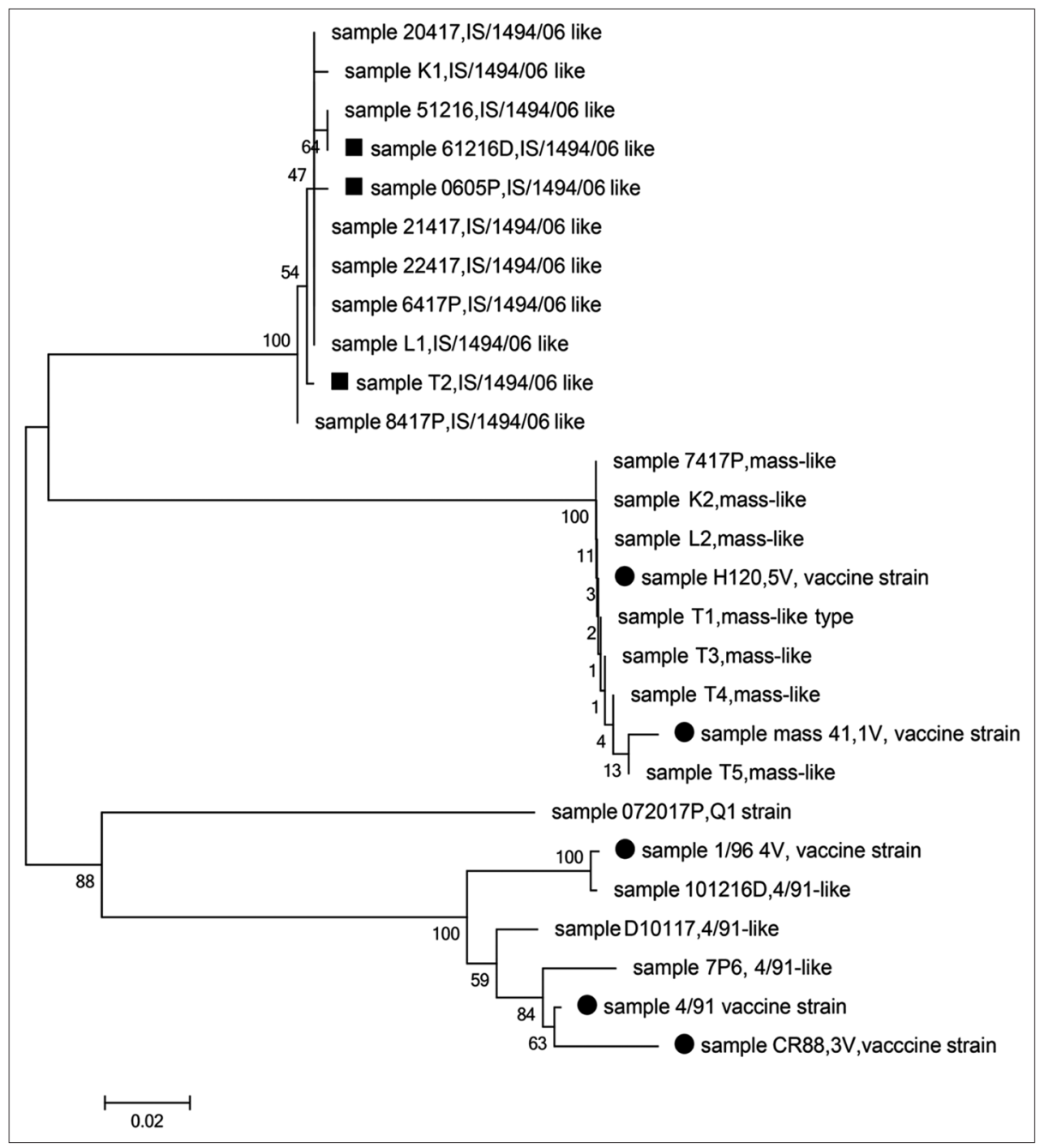

Figure-3: Phylogenetic tree analysis of the partial spike 1 gene sequences of IBV vaccine strains and field isolates. The solid circle is the IBV vaccine strains. The solid squares are the mismatched IBV (in HRM analysis, those isolates were clustered in cluster 2 (Mass-like type), but in sequencing, they were of IS/1494/06 like). The evolutionary history was inferred using the neighbor-joining method. The percentage of replicate trees in which the associated taxa clustered together in the bootstrap test (1000 replicates) is shown next to the branches. There were a total of 315 positions in the final dataset. Evolutionary analyses were conducted in MEGA6. 
performed on local IBV vaccine and field strains [16]. Of the 17 IBV-positive cases, only 12 were typed correctly with matching HRM/3'UTR and S1 gene sequencing results [16]. As can be seen, our HRM assay can type any Mass or 4/91 IBV vaccine and field strain correctly to their corresponding cluster. However, a problem is only encountered when dealing with IBV variant II field strain. In such cases, we might need to confirm the results of the HRM assay by sequencing of the $\mathrm{S} 1$ gene.

Regarding cluster 3, the variant II-like (1S/1494/06-like) stain is an endemic IBV strain in Jordan that is involved in the respiratory, kidney, and reproductive tract problems $[23,24]$. Recently, the variant II-like (1S/1494/06-like) field strain has been found to be subject to multiple recombination events, which might explain the wide range in melting temperatures in cluster 3 [25].

Concerning cluster 4, sample 072017 was found to belong to the unique Q1 strain, which was first reported in China, in 1996, and then in Italy during a 2011 outbreak in broilers [26,27]. Even though the melting point for this sample is similar to those in other clusters, HRM and ScreenClust analysis were able to differentiate it into a separate cluster.

\section{Conclusion}

Our qRT-PCR with HRM/spike gene assay was able to genotype all vaccine IBV strains and cluster them into separate clusters according to their distinct genotypes (Mass and Mass-like cluster, 4/91 and 4/91like cluster). Most of the IBV field samples belonged to the variant II-like (1S/1494/06-like) strain. Those variant II-like (1S/1494/06-like) strains were all classified into one cluster expect for three samples that were clustered within the Mass and Mass-like IBV strains. The current qRT-PCR/HRM curve analysis was able to detect and rapidly identify novel and vaccine-related IBV strains which are confirmed by S1 gene nucleotide sequencing, making it a rapid and cost-effective tool.

\section{Authors' Contributions}

MA and OA designed the experiment. OA performed the technical assays. MA and MBA supervised the technical assays, MA and OA analyzed the results. MA and OA prepared the manuscript. All authors read and approved the final manuscript.

\section{Acknowledgments}

The authors would like to thank Ms. Amneh Tarkhan for her excellent technical assistance and valuable comments. The author expresses a deep appreciation and thanks to the Deanship of Research at Jordan University of Science and Technology for its financial support of this work (Grant \# 195/2018).

\section{Competing Interests}

The authors declare that they have no competing interests.

\section{Publisher's Note}

Veterinary World remains neutral with regard to jurisdictional claims in published institutional affiliation.

\section{References}

1. Roussan, D.A., Khawaldeh, G.Y. and Shaheen, I.A. (2009) Infectious bronchitis virus in Jordanian chickens: Seroprevalence and detection. Can. Vet. J., 50(1): 77-80.

2. Bande, F., Arshad, S.S., Omar, A.R., Hair-Bejo, M., Mahmuda, A. and Nair, V. (2017) Global distributions and strain diversity of avian infectious bronchitis virus: A review. Anim. Health Res. Rev., 18(1): 70-83.

3. Cavanagh, D. (2003) Severe acute respiratory syndrome vaccine development: Experiences of vaccination against avian infectious bronchitis coronavirus. Avian Pathol., 32(6): 567-582.

4. Jackwood, M.W. (2012) Review of infectious bronchitis virus around the world. Avian Dis., 56(4): 634-641.

5. Terregino, C., Toffan, A., Beato, M.S., De Nardi, R., Vascellari, M., Meini, A., Ortali, G., Mancin, M. and Capua, I. (2008) Pathogenicity of a QX strain of infectious bronchitis virus in specific pathogen-free and commercial broiler chickens, and evaluation of protection induced by a vaccination programme based on the Ma5 and 4/91 serotypes. Avian Pathol., 37(5): 487-493.

6. Sun, C., Han, Z., Ma, H., Zhang, Q., Yan, B., Shao, Y., $\mathrm{Xu}$, J., Kong, X. and Liu, S. (2011) Phylogenetic analysis of infectious bronchitis coronaviruses newly isolated in China, and pathogenicity and evaluation of protection induced by Massachusetts serotype H120 vaccine against QX-like strains. Avian Pathol., 40(1): 43-54.

7. Lisowska, A., Sajewicz-Krukowska, J., Fusaro, A., Pikula, A. and Domanska-Blicharz, K. (2017) First characterization of a Middle-East GI-23 lineage (Var2-like) of infectious bronchitis virus in Europe. Virus Res., 242(1): 43-48.

8. Thor, S.W., Hilt, D.A., Kissinger, J.C., Paterson, A.H. and Jackwood, M.W. (2011) Recombination in avian gamma-coronavirus infectious bronchitis virus. Viruses, 3(9): 1777-1799.

9. Leyson, C., Franca, M., Jackwood, M. and Jordan, B. (2016) Polymorphisms in the S1 spike glycoprotein of Arkansastype infectious bronchitis virus (IBV) show differential binding to host tissues and altered antigenicity. Virology, 498(11): 218-225

10. Cavanagh, D., Picault, J.P., Gough, R., Hess, M., Mawditt, K. and Britton, P. (2005) Variation in the spike protein of the 793/B type of infectious bronchitis virus, in the field and during alternate passage in chickens and embryonated eggs. Avian Pathol., 34(1): 20-25.

11. Cavanagh, D., Elus, M.M. and Cook, J.K. (1997) Relationship between sequence variation in the S1 spike protein of infectious bronchitis virus and the extent of cross-protection in vivo. Avian Pathol., 26(1): 63-74.

12. Ladman, B.S., Loupos, A.B. and Gelb, J. Jr. (2006) Infectious bronchitis virus $\mathrm{S} 1$ gene sequence comparison is a better predictor of challenge of immunity in chickens than serotyping by virus neutralization. Avian Pathol., 35(2): 127-133.

13. Valastro, V., Holmes, E.C., Britton, P., Fusaro, A., Jackwood, M.W., Cattoli, G. and Monne, I. (2016) S1 genebased phylogeny of infectious bronchitis virus: An attempt to harmonize virus classification. Infect. Genet. Evol., 39(4): 349-364.

14. Ababneh, M., Dalab, A.E., Alsaad, S. and Al-Zghoul, M. (2012) Presence of infectious bronchitis virus strain CK/ $\mathrm{CH} / \mathrm{LDL} / 97 \mathrm{I}$ in the Middle East. ISRN Vet Sci., 2012(4): 201721.

15. Ganapathy, K., Ball, C. and Forrester, A. (2015) Genotypes of infectious bronchitis viruses circulating in the Middle 
East between 2009 and 2014. Virus Res., 210(12): 198-204.

16. Hewson, K.A., Browning, G.F., Devlin, J.M., Ignjatovic, J. and Noormohammadi, A.H. (2010) Application of high-resolution melt curve analysis for classification of infectious bronchitis viruses in field specimens. Aust. Vet. J., 88(10): 408-413.

17. Kalthoff, D., Beer, M. and Hoffmann, B. (2013) High resolution melting analysis: Rapid and precise characterization of recombinant influenza A genomes. Virol. J., 10(9): 284.

18. Erster, O., Stram, R., Menasherow, S., Rubistein-Giuni, M., Sharir, B., Kchinich, E. and Stram, Y. (2017) Highresolution melting (HRM) for genotyping bovine ephemeral fever virus (BEFV). Virus Res., 229(2): 1-8.

19. Gelaye, E., Mach, L., Kolodziejek, J., Grabherr, R., Loitsch, A., Achenbach, J.E., Nowotny, N., Diallo, A. and Lamien, C.E. (2017) A novel HRM assay for the simultaneous detection and differentiation of eight poxviruses of medical and veterinary importance. Sci Rep., 7(2): 42892.

20. Er, T.K. and Chang, J.G. (2012) High-resolution melting: Applications in genetic disorders. Clin. Chim. Acta, 414(12): 197-201.

21. Steer, P.A., Kirkpatrick, N.C., O'Rourke, D. and Noormohammadi, D. (2009) Classification of fowl adenovirus serotypes by use of high-resolution melting-curve analysis of the hexon gene region. J. Clin. Microbiol., 47(2): 311-321.
22. Chamings, A., Nelson, T.M., Vibin, J., Wille, M., Klaassen, M. and Alexandersen, S. (2018) Detection and characterization of coronaviruses in migratory and non-migratory Australian wild birds. Sci. Rep., 8(1): 5980.

23. Zanaty, A., Arafa, A.S., Hagag, N. and El-Kady, M. (2016) Genotyping and pathotyping of diversified strains of infectious bronchitis viruses circulating in Egypt. World J. Virol., 5(3): 125-134.

24. Mousavi, F.S., Ghalyanchilangeroudi, A., Hosseini, H., Fasaei, B.N., Ghafouri, S.A., Abdollahi, H., FallahMehrabadi, M.H. and Sadri, N. (2018) Complete genome analysis of Iranian IS-1494 like avian infectious bronchitis virus. Virus Dis., 29(3): 390-394.

25. Kiss, I., Mato, T., Homonnay, Z., Tatar-Kis, T. and Palya, V. (2016) Successive occurrence of recombinant infectious bronchitis virus strains in the restricted area of Middle East. Virus Evol., 2(2): vew021.

26. Toffan, A., Bonci, M., Bano, L., Bano, L., Valastro, V., Vascellari, M., Capua, I. and Terregino, C. (2013) Diagnostic and clinical observation on the infectious bronchitis virus strain Q1 in Italy. Vet. Ital., 49(4): 347-355.

27. Franzo, G., Listorti, V., Naylor, C.J., Lupini, C., Laconi, A., Felice, V., Drigo, M., Catelli, E. and Cecchinato, M. (2015) Molecular investigation of a full-length genome of a Q1-like IBV strain isolated in Italy in 2013. Virus Res., 210(12): $77-80$.

\section{$* * * * * * * *$}

